\title{
A Teacher's Perspective Of ICT Integration IN SAUDI SECONDARY SCHOOLS
}

\author{
Abdullah Alenezi \\ Northern Borders University, Arar, Saudi Arabia
}

\begin{abstract}
The Mandatory use of ict in saudi secondary schools within the framework of the ict-related educational reform is a response to the requirements of the digital age. however, there is a discrepancy between what teachers want to do to promote ict integration and what they can really do since they are limited by poor equipment. Saudi Arabia Has Difficulties moving on from the transition stage of ICT adoption and adaptation to wide-scale ict integration. although all saudi teachers are ict adopters, they are reluctant to adapt western uses of ict tools without understanding their cultural appropriateness with regard to the specific saudi context that is deeply grounded in a multi-century islamic tradition of teaching. this article explores technical, political, and cultural appropriateness of ict tools in saudi secondary schools with a view to promoting ict integration from the mandatory adoption stage to ict integration.
\end{abstract}

\section{KEYWORDS}

ICT integration, ICT adoption, ICT implementation, early adopters, late adopters, Saudi educational reform, stages of concern, levels of use, implementation factors

\section{INTRODUCTION}

Under the pressure of economic globalization, the ICT-related reform of education is in progress in Saudi secondary schools. Its uniform educational policies and guidelines have been approved by the Supreme Council of Education (Alshumaim and Alhassau, 2010). This strategic framework directs teacher development practices toward the pedagogical uses of technology. Saudi teachers face the reality of a gradual shift from more traditional pedagogies to technologically advanced ones. However, the digital divide, cultural inertia with regard to individual attitudes to ICT integration in all spheres of life, a lack of strategic planning to address the problem of insufficient computer training, and the need for efficient ICT-related programs have impeded ICT integration in the Saudi context. Before the start of the educational reform (1991-2004) the uses of ICT were fragmentary in Saudi school environments. Early adoption contributed to increased awareness of regulated uses of ICT, made the presence of computers a reality, and exposed Saudi schools to the global trend of using ICT for educational purposes and educational reform. Late adoption within the framework of the Saudi educational reform (since 2004 up to the present) has turned all Saudi teachers into mandatory ICT adopters. However, both early and late adopters share similar concerns about motivation, goals, resources, and standards with regard to ICT integration.

The objective of this study was to explore the specifics of ICT integration in a Saudi secondary school context. It is significant for the future of the reform to find out how the context of mandatory uses of technology in Saudi secondary schools influences adoption and adaptation within transformative change from ICT adoption to ICT implementation. 
International Journal on Integrating Technology in Education (IJITE) Vol.8, No.2, June 2019

First, I will introduce the Saudi mandatory context of ICT adoption in secondary schools. Second, I will define methodological issues of the present research. Third, I will describe this study's research design. Fourth, I will focus on the findings. Finally, I will discuss the importance of technical, political, and cultural implementation factors in the overall process of ICT adoption, implementation, and integration.

\section{BACKGROUND}

The current literature discusses global challenges posed by teaching with technology. Most of the published research to date focuses on technological advancement. There is a growing demand for exploring a strategic emphasis on alternative teaching with technology (Jones and O'Shea, 2004). This demand is justified by the assumption that modern educational continuums have to respond to improvement cycles in ICT integration by strategic planning. As a result, teacher professional development is at the core of educational change.

However, there is discrepancy between the concepts of ICT adoption, ICT integration, and ICT implementation. ICT integration is often viewed as a phased process with ICT adoption as one of its phases. ICT integration is the ultimate goal of transformative change in the system of education, which can be achieved through ICT implementation. Hence, ICT implementation is a process inherent in ICT integration.

The Arab world has met this challenge of teaching school subjects with technology, being involved in a modern-day response to the demands of the digital age and rapid technological advances. Saudi Arabia takes part in this process, regulating at the government level that knowledge management via technology needs to be integrated into teaching and learning activities in order to respond to today's highly technological educational standards. Within this current pressing issue, Saudi Arabia faces up to the reality of creating technology-based infrastructure, enhancing access to devices, and improving ICT procurement attributable to mentoring systems. The globalized world puts pressure on Saudi Arabia with regard to adaptation or what can be locally considered as a Western pattern of ICT integration.

Worldwide, ICT-related transformative change can be effective only when schools strategically plan the personalization of learning through ICT integration. It is apparent that the entire process of ICT integration combines social penetration in a virtual educational environment with the flexibility of ICT availability and identification of key features at every stage within the process of ICT implementation (Passey, 2006).

Secondary education systems around the world share some problems with the use of technology in schools. In his analysis of technology-enhanced learning in British schools, Passey (2006) identifies such problems for ICT integration as identification of the roles of ICT and learning, the nature and processes of learning with technology, impacts of discrete forms of ICT on the teaching and learning process, and adequate pedagogical uses of each technology. In their study of collaborative learning in Spanish schools, Garcia-Valcarcel and co-authors (2014) claim that there is a strong demand for transformative change dealing with curriculum development, collaborative projects, teacher professional development, increased student learning, promoting student motivation and satisfaction, among other issues.

Saudi Arabia invests in the process of economic globalization by giving priority to its educational reform. However, this call for change has never been radical. The system of Saudi education remains rooted in the tradition whose stability is not easily shaken. It appears that the fundamentals of the Saudi educational system - with its emphasis on religious instruction that questions powers of any outside influences- have proven to be enduring pillars. Islamic, Arab, 
International Journal on Integrating Technology in Education (IJITE) Vol.8, No.2, June 2019

and local properties are at the core of the Saudi collective identity, which the public school curriculum has promoted thus far. The role of technology within this well-established system is not clear, so the presence of ICT tools in schools is rather formal than innovative. There are difficulties introducing a new ICT-related culture in Saudi schools because it seems to be in conflict with Islamic culture that dominates all spheres of life. Islam and progress have been interconnected in a compromised mandate to ICT adoption. But formally turning all Saudi teachers into ICT adopters did not mean balancing technology with the pillars of Islamic knowledge and thinking. The present ICT-related difficulties in the Saudi context reveal doubts about ICT adoption as adaptation of what is taken for a Western pattern of ICT integration. This ICT-related openness to the global world seems to be damageable to cultural appropriateness of technology in a specific Saudi context. Henceforth, Saudi teachers need national direction that contextualizes the ICT implementation process. For example, the use of websites and social networking in schools can be in conflict with the established tradition.

ICT integration in Saudi secondary schools can be divided into two main phases: before the educational reform was initiated (1991-2004) and after it was launched as a ten-year implementation plan (2004-2014). In Saudi Arabia, ICT was introduced three decades ago, in 1985. This breakthrough in a highly traditional system of education gave way to such computerrelated subjects as computer sciences, programming in BASIC, and systems programming and the use of information systems. It was the first step towards ICT integration viewed as the presence of ICT in Saudi secondary schools. In 1991, computer science related subjects were included in the curriculum, first in the schools for boys and later in the schools for girls. Since 1999, secondary schoolchildren have studied Information Technology, Computer Science, Computer Application, Information Systems, and the Information Age (Oyaid, 2009). During that first phase, ICT adoption had no administrative support from above, as it solely depended on the initiative of individual teachers who were early ICT adopters. At that time, integration of ICT in curriculum meant the integration of computer science related subjects as courses of study. There was no requirement for all Saudi teachers to be ICT adopters.

The second phase legalized the presence of ICT in Saudi schools. Before the reform, individual teachers were responsible for facilitating knowledge management using elements of electronic learning. Today, within the reform framework, all teachers are mandated to use ICT. They take Intel ${ }^{\circledR}$-sponsored courses in computers in their schools and participate in training programs held in their school districts. To illustrate the point, in 2011 over 1,700 male and female teachers from 50 Saudi schools took part in a training program initiated by the national Tatweer project in Taif, Abha, and Jeddah. These teachers learned how to replace conventional teaching methods with the use of computer technologies. In order to change teaching practices to incorporate technology, Saudi teachers take a proficiency exam and automatically become ICT adopters (Al-Kinani, 2011).

However, ICT integration in Saudi secondary schools does not go further than mandatory ICT adoption. The context of ICT adoption is maintained, but the transition from ICT adoption to ICT integration through the process of ICT implementation shows little progress. Although financial investments are high, their equal distribution among Saudi schools remains a problem. Technically, the Saudi schools are poorly equipped with technology in their classroom settings. Politically, the Saudi choice of ICT adoption fails dynamism in terms of ICT integration whose process repeatedly focuses on ICT adoption. The mandatory use of ICT in Saudi schools reduces administrative support of local authorities. Culturally, the country is in conflict with faithfulness to local traditions and innovativeness of the digital age. All this put together, Saudi Arabia has not yet developed a new culture of integrated uses of technology in secondary schools. The Ministry of Education borrows the existing patterns to keep pace with the rest of the world but schools are inactive because they lack tools available and depend on what is given to them. As a result, Saudi 
International Journal on Integrating Technology in Education (IJITE) Vol.8, No.2, June 2019

teachers have no clear vision of what to do with the given mandate that delegates the Saudi teachers no authority in selecting those ICT tools that are technically, politically and culturally appropriate to the Saudi context.

\section{METHODOLOGY}

The question of ICT integration in the context of mandatory ICT adoption is studied by addressing adoption theories that identify the dimensions of technology implementation. Adoption theories focus on the process that modifies school settings with regard to the diffusion of technology. Although most adoption theories often consider ICT adoption for learning and teaching purposes separately, a study by Alwani and Soomro conducted in the Saudi context demonstrates the efficacy of the adoption model. These scholars scale ICT adoption by Saudi teachers of science in accordance with four phases: 0 - not familiar with ICT, 1 - entry, 2 adoption, and 3 - transformation. To them, ICT adoption is some familiarity with the uses of how ICTs can support classroom practices and teaching strategies. They hold the view that transformation, as phase higher in the hierarchy, reveals a significant change in teacher practices and results in new curricula and teaching/learning techniques (Alwani and Soomro, 2010). The adoption model is useful for the present research because it considers ICT integration into teacher practices as a phased process and determines the next phase that follows ICT adoption. This model indicates the initial phase of adoption and further activities related to their integration into the process of education (Passey, 2010). As all adopters become users of ICT due to the mandate, the adoption model becomes integrated into the implementation model. The combination of adoption theory with technology implementation highlights the specifics of the implementation process related to a phased approach to ICT adoption, as ICT adopters are expected, sooner or later, eventually turn into ICT implementers.

Rogers' theory of the diffusion of innovations (Rogers, 2003) is utilized to analyze the ICT adoption patterns in various contexts (Richardson, 2011). Rogers' phased approach to diffusion has been found to be appropriate by many education researchers. For example, the diffusion approach has been widely and successfully applied by higher education researchers (Smart, 2010). In the Saudi context, the innovation-decision process can be identified as the mandate of ICT integration within the educational reform framework. Yet, Rogers' theory fails to take into account key dimensions of the cultural logic of innovation. It offers a quantitative instrument for considering ICT adoption, but there is a strong need for elucidating the entire process of ICT implementation without its being disconnected from ICT adoption. In the Saudi context with mandatory ICT adoption, it is continuity of the holistic process of ICT implementation, beyond mechanical ICT adoption that can be considered to be nationally specific.

The cultural logic of ICT integration is taken into account by implementation theories. Some of them consider ICT integration to be a stage in the process of adopting an innovation, while others advance models of change within integration theory. It is methodologically relevant to the present study that ICT implementation is the process that facilitates achieving the ultimate goal of ICT integration. From this viewpoint, ICT integration is both the product and the process of ICT implementation.

Although the Saudi context is grounded in mandatory ICT adoption within the ICT implementation process, Klein and Knight claim that ICT adoption is not an obligatory prerequisite for ICT implementation. These scholars identify six key factors of innovationimplementation effectiveness: 1) a package of implementation policies and practices, 2) a climate conducive to innovation implementation, 3) administrative support, 4) the availability of financial resources, 5) a learning orientation, 6) a long-term time orientation (Klein and Knight, 2005). Passey (2010) assumes that the process of change through ICT integration consists of the "self" 
International Journal on Integrating Technology in Education (IJITE) Vol.8, No.2, June 2019

phase, the "task" phase, and the "impact" phase. These phases link ICT adoption with ICT implementation by showing that only completing one phase, like ICT adoption in the Saudi secondary school environment, can lead to another phase that has its own features and is influenced by the factors that are specific to it. In the Saudi context, the "task" phase is the transition from ICT adoption to a higher hierarchical level of ICT implementation which is not clearly formulated so far.

The concerns-based adoption model (CBAM) conceptualizes change as a teacher's developmental personal process and is validated as a long-term measurement system (Wiggins and McTighe, 2007). The CBAM offers the best explanation for teacher development practices in the Saudi secondary school context of ICT integration for such reasons. First, the CBAM uses a standard set of stages of concern and levels of use to describe teachers' concerns about how ICT integration will affect teacher development practices. Second, it helps define what aids Saudi teachers to move from one stage of concern and levels of ICT use to another stage and what stages of concern and levels of use dominate in the Saudi context in these subject areas. Third, it has proven to be an effective instrument that details teacher concerns about technology implementation over multiple levels of use (Brooks-Young, 2002).

Similar to adoption and implementation models, the CBAM addresses change as a phased process (Hall, 2010). This model is relevant for evaluating ICT use in Saudi schools, for it classifies the stages of concern and levels of use that have been shown to be valid by other researchers. Moreover, this theory categorizes awareness, informational, and personal stages under "self concern", management stages under "task concern" and consequence, and collaboration and refocusing stages under "impact concern". Finally, this model implies that when teachers are inclined to "self concern," they are more concerned about themselves. On the other hand, when teachers are inclined to "task concern," they are more concerned about technology ("effect concern"), which indicates that teachers' concerns relate to the impact of the technology on the teaching and learning process.

The grounded theory approach is utilized to identify pedagogical content development in interconnectedness between domain-specific and tool-specific teaching with technology (McGrory, 2004). The constructivist version of grounded theory is valuable for this study due to its interpretive powers that validate qualitative research in a secondary school setting.

\subsection{RESEARCH DESIGN}

This case study relies on a semi-prepared interview as the main instrument of research. The male researcher who conducted interviews in 2012 with the Saudi male teachers of mathematics, science, and Arabic and his trained female assistant who conducted interviews with the Saudi female teachers of the same subject domains used the same interview questions. These questions were preliminary tested on 3 male and 3 female teachers representing each subject domain. The main study was based on the interviews of 18 teachers of mathematics, science, and Arabic who work in Arar, Tarayf, and Rafha, the governorates belonging to the Saudi Northern Borders province that represents the education district in which the data were collected. This part of the country is the least populated part of Saudi Arabia where more than 320,000 people live. The choice of this education district was justified for the following reasons. First, the Northern Borders province is far from the central parts of Saudi Arabia, so the educational reform can develop peculiarities with respect to other parts of Saudi Arabia. Second, no research has been conducted on ICT integration in this district, as the pilot projects of the Saudi educational reform are implemented in big urban centres such as Jeddah and Riyadh. Third, the teachers in this district can be less dependent on the guidelines of the Ministry of Education. 
International Journal on Integrating Technology in Education (IJITE) Vol.8, No.2, June 2019

The distribution of schools was equally sampled from each of the three governorates: two schools for boys and two schools for girls in Arar, two schools for boys and two schools for girls in Rafha, and two schools for boys and two schools for girls in Turayf. The criteria for selecting participants were: (i) the participants were subject teachers in three subject domains: mathematics, science, and Arabic, (ii) each subject teacher worked in a different school, although three teachers that teach one of the three subjects may be from the same school, (iii) half of the participants work in a school for boys and half of them work in a school for girls, and (iv) teachers from schools for boys and from schools for girls were equally represented.

This study used stratified purposeful sampling to facilitate group comparison. Three teachers in each specific subject domain (mathematics, science, and Arabic) were interviewed from each school. Each governorate was represented by 6 teachers from at least 2 schools. The parity between schools for boys and schools for girls was retained for avoiding discriminatory data collection in the Saudi context of segregated schooling.

The transcribed and translated interviews were scored using stages of concern so that each instance of talk was coded with a stage of concern ranging from 1-6 corresponding to the CBAM model: Stage 0 - awareness level, Stage 1 - level of information, Stage 2 - personal level, Stage 3 - management level, Stage 4 - level of consequence, Stage 5 - collaboration level, and Stage 6 level of refocusing. The levels of use describe the current state of each ICT adopter. They were encoded consistent with the work of Hall (2010, p. 236): VI - Renewal (the teacher is seeking more effective alternatives to ICT integration), $\mathrm{V}$ - Integration (the teacher is making deliberate efforts to coordinate with other teachers about ICT use), IVB - Refinement (the user is making changes to better the outcomes of ICT uses), IVA - Routine (the teacher is making few or no changes and has an established pattern of ICT use), III - Mechanical use (the teacher is using ICT in a poorly coordinated manner), II - Preparation (the teacher is preparing to use ICT), I Orientation (the teacher is seeking out information about ICT use), and $\mathrm{O}$ - Non-use (the teacher takes no action with respect to ICT use).

Both stages of concern and levels of use were used as working codes. A category emerged from the combinations between stages of concern and levels of use that were outlined from the interview. The use of the CBAM scales helped the researcher move from and back into a defined category that reinterpreted those recognized scales by linking stages of concern and levels of use within one category.

To remain consistent with grounded theory studies, the data were analyzed using a constant comparative method of data analysis. The constant comparative method facilitated examining and reexamining the data by comparing all of the data that were collected (Yamagata-Lynch, 2010). One segment of data was compared with another segment and similarities and differences were determined. The data were grouped on a similar dimension, which became a category. The core category was identified by emerged combinations between stages of concern and levels of use. Other categories were connected through that core category (Merriam, 2009, pp. 30-31). Patterns were identified by comparing incident with incident, incident with category, and category with category. Similar incidents shared basic properties of a defined category and differences between incidents established coding boundaries.

\section{RESUlts AND FindingS}

Based on the interviews conducted, the combined patterns related to stages of concern and levels of use were identified. These patterns were grouped into the following categories. 
International Journal on Integrating Technology in Education (IJITE) Vol.8, No.2, June 2019

1. "Mandatory ICT implementation to change a classroom atmosphere". Based on the responses of the participants, ICT integration at the information stage of concern combined with the preparation level of use was defined as the category "mandatory ICT implementation to change a classroom atmosphere." The characteristic features of this category were: (i) it was limited only to Arabic teachers from across the sample, (ii) it was limited to late (mandatory) adopters of ICT who have no training in ICT, and (iii) there was a strong belief that the subject domain did not require ICT, although ICT implementation would make a change in a classroom atmosphere but would not influence the process of teaching Arabic in general.

2. "ICT implementation saves time and effort but it is supportive". Based on the responses of the interviewed teachers, ICT integration at the information stage of concern combined with the mechanical level of use was defined as the category "ICT implementation saves time and effort but it is supportive." This category was identified among the Saudi teachers of science and mathematics. Those instructors were aware of the presence of ICT in schools and were informed, as they highlighted in their interviews, from their personal experience that ICT saved time and effort, made lessons more interesting, and connected students with reality. Teachers in this category were limited in their uses of ICTs (projector, educational television, projector or computer) and had little training, so they employed a limited number of tools. Their ICT usage depended on the availability of ICTs in their schools. They believed that ICT was supplemental to other teaching methods. For example, the male science teacher from Rafha thought that the use of ICT made no significant difference in his teaching practices. He valued technology for its ability to connect students with reality and its assistance in changing a teaching method. However, this teacher did not consider technology to be a teaching method that had a value of its own. On the whole, the teachers that referred to this emerging category were informed about the mandatory presence of ICTs in schools but they did not know how to use ICTs effectively.

3. "ICT implementation is necessary in modern learning and teaching". ICT integration at the personal stage of concern combined with the mechanical level of use characterized half of the teachers of Arabic, both male and female, and one female teacher of science. It appears that there might be a gender bias here (three females, one male). It is worth noting that each of the female respondents was from a different province. This category is defined as "ICT implementation is necessary in modern learning and teaching." All respondents in this category were influenced by mandatory uses of ICT, so they expected support from the Ministry of Education in the form of products that facilitated teaching and learning (the only male teacher in the category expected CDs from the Ministry of Education). The female teachers that mainly constituted this category wanted to receive more training (the female teacher of Arabic from Arar), emphasize the role of ICT in participatory learning and student concentration (the female science teacher from Turayf), or use ICTs for reducing writing on the blackboard via the use of a projector (the female teacher of Arabic from Rafha).

4. "ICT implementation as the start of ICT integration into the curriculum". ICT integration at the management stage of concern combined with the mechanical level of use is categorized as "ICT implementation as the start of ICT integration into the curriculum." All teachers in this category took training courses and had experience in using ICT. It is worth noting that they all taught different subjects: a male teacher of mathematics from Turayf, a male teacher of Arabic from Turayf, and a female teacher of science from Arar. All of the teachers in this category were aware of the presence of ICT in the world and the necessity of it being integrated into the school curriculum because students love technology, the modern world is ICT-related, Saudi students have fun when ICTs are used in the classroom, girls become more focused, and all students prosper from the use of ICT. However, objectively all of these teachers were constrained by mechanical uses because they had no or limited access to ICTs in workable condition in the 
International Journal on Integrating Technology in Education (IJITE) Vol.8, No.2, June 2019

classroom but the tools could not be moved from the Learning Resources Centre. At the same time, these teachers used ICT as often as is possible.

5. "ICT implementation for teacher personal growth and student motivation". ICT integration at the management level of use combined with the refinement or routine levels of use was categorized as "ICT implementation for teacher personal growth and student motivation." Of the teachers of science and mathematics in this group, only one was a female teacher of mathematics who spoke about personal growth concerning ICT use and the responsibility of teachers for integrating ICT into the educational environment. Although some teachers had a relatively long history of using ICT over their teaching career (the male teacher of mathematics from Arar had used ICT since 2003 after completing a training course at his own expense) and others were novices (a female teacher of mathematics from Turayf had been using ICT since 2010), they shared several commonalities: (i) they felt responsible for ICT use in the classroom and they tried to excel at using sources that were available, such as a projector, (ii) they used ICTs regularly, although they felt that the usage could be increased (the male teacher of science from Turayf used ICT 2-3 times per week and did not think that ICT was used enough), (iii) they valued the presence of ICTs in the classroom as a means of student motivation by simplifying and explaining the material delivered in the classroom, and (iv) they knew that ICT use was necessary for personal growth.

The mandatory usage of ICT leads to the combination of a management stage of concern with a mechanical level of use, which is shared by teachers of mathematics, science, and Arabic. This situation implies that the teachers that we interviewed seek ways of adapting to the presence of ICT in a classroom setting. However, they do so mechanically, without knowing the outcomes of their management approaches. They seem to be waiting for further instructions and deliberately retain the concerns outlined above.

The mandatory usage of ICT tools is required for a transition stage moving from ICT adoption to ICT implementation. The mandatory uses involve three initial stages of concern $(1-$ information stage of concern, 2 - personal stage of concern, and 3 - management stage of concern) and three levels of use (II - preparation level of use, III - mechanical level of use, and IV integration/refinement level of use). Further development is impeded since even earlier adopters have difficulty in rising above the management level of concern.

The phased movement within the transition stage can be represented by four sequential steps:

Step 1: From 1/II (information stage of concern/ preparation level of use) to 1/III (information stage of concern/mechanical level of use). The goal of the transition is the informed mechanical use of ICT within the framework of Saudi ICT-related educational reform.

Step 2: From 1/III (information stage of concern/ mechanical level of use) to 2/III (personal stage of concern/mechanical level of use). The goal of the transition is the personal mechanical use of ICT within the framework of Saudi educational reform.

Step 3: From 2/III (personal stage of concern/mechanical level of use) to 3/III (management stage of concern/ mechanical level of use). The goal of the transition is the managed mechanical use of ICT.

Step 4: From 3/III (management stage of concern/mechanical level of use) to 3/IV (management stage of concern/ integration or refinement level of use). The goal of the transition is the managed and refined use of ICT on a regular basis. 
International Journal on Integrating Technology in Education (IJITE) Vol.8, No.2, June 2019

There are no barriers to Step 1, since ICT-related educational reform is mandatory. In their transition to Step 2 teachers should be personally motivated to use ICT tools as they are mandated by the Ministry of Education. The barrier to this step is a lack of rewards and appraisals related to the ICT-related personal initiative in a school setting. There are three barriers to the transition from Step 2 to Step 3. At this stage, the number of teachers who mechanically use ICT tools exceeds the availability of such tools in a school setting. Saudi teachers of Arabic, for example, complain about science teachers who, in their view, have a better opportunity to teach with technologies. Also, at this stage teachers feel that the traditional methods of education are separated from an ICT-related method of education. It is not clear whether ICT uses are supportive of the traditional methods of education or an ICT-related method of education has a value of its own. What is more, at this stage teachers start to consider the appropriateness of those ICT tools that are available to them in their school setting. The transition to Step 4 is possible when teachers are enthusiasts of a new ICT-related method of teaching because they understand that it represents openness to the digital world, enhances classroom interaction, increases student participation and cognitive activity, and changes a school setting drastically. Management, however, remains of concern because the availability of ICT tools in a school setting is not sufficient and school administration fails to reward ICT-related teacher efforts in a stimulating way.

This is summarized in Table 1 below.

Table 1. The Phased Movement within the Transition Stage in Saudi Secondary Schools

\begin{tabular}{|c|c|c|}
\hline $\begin{array}{l}\text { Steps within the phased } \\
\text { movement }\end{array}$ & $\begin{array}{l}\text { Barriers to ICT integration } \\
\text { related to the corresponding } \\
\text { step }\end{array}$ & $\begin{array}{l}\text { Teacher involvement in the } \\
\text { process. }\end{array}$ \\
\hline $\begin{array}{l}\text { 1. From } 1 / \mathrm{II} \text { (information stage } \\
\text { of concern/ preparation level of } \\
\text { use) to } 1 / \mathrm{III} \text { (information stage } \\
\text { of concern/mechanical level of } \\
\text { use). }\end{array}$ & $\begin{array}{l}\text { No barriers because of the } \\
\text { mandate. }\end{array}$ & $\begin{array}{l}\text { All teachers are mandated to } \\
\text { be ICT adopters in compliance } \\
\text { with the reform. }\end{array}$ \\
\hline $\begin{array}{l}\text { 2. From 1/III (information } \\
\text { stage of concern/ mechanical } \\
\text { level of use) to } 2 / \mathrm{III} \text { (personal } \\
\text { stage of concern/mechanical } \\
\text { level of use). }\end{array}$ & $\begin{array}{l}\text { A lack of rewards and appraisals, } \\
\text { no personal motivation. }\end{array}$ & $\begin{array}{l}\text { All teachers are obliged to use } \\
\text { ICT tools but they are free to } \\
\text { consider regularity of ICT } \\
\text { uses. }\end{array}$ \\
\hline $\begin{array}{l}\text { 3. From } 2 / \mathrm{III} \text { (personal stage of } \\
\text { concern/mechanical level of } \\
\text { use) to } 3 / \mathrm{III} \text { (management stage } \\
\text { of concern/ mechanical level of } \\
\text { use). }\end{array}$ & $\begin{array}{l}\text { The number of ICT adopters } \\
\text { exceeds the availability of ICT } \\
\text { tools: the traditional methods are } \\
\text { separated from ICT-related } \\
\text { methods; appropriateness of ICT } \\
\text { uses is not clear. }\end{array}$ & $\begin{array}{l}\text { Teachers manage regularity of } \\
\text { ICT uses to enhance } \\
\text { appropriateness and develop } \\
\text { ICT-related methods. }\end{array}$ \\
\hline $\begin{array}{l}\text { 4. From 3/III (management } \\
\text { stage of concern/mechanical } \\
\text { level of use) to } 3 / \mathrm{IV} \\
\text { (management stage of concern/ } \\
\text { integration or refinement level } \\
\text { of use). }\end{array}$ & $\begin{array}{l}\text { Management of teaching with } \\
\text { technology. }\end{array}$ & $\begin{array}{l}\text { Teachers work with ICT tools } \\
\text { because they know what } \\
\text { appropriate ICT uses can } \\
\text { change teacher practices. }\end{array}$ \\
\hline
\end{tabular}

\section{DISCUSSION}

The Saudi ICT-related educational reform is impeded by technical, political, and cultural implementation factors. The Saudi secondary school teachers have difficulty moving from 
International Journal on Integrating Technology in Education (IJITE) Vol.8, No.2, June 2019

mandatory ICT adoption to higher stages of concern and levels of use. They lack a pattern of ICT uses that is culturally appropriate to their educational context.

\section{Technical implementation factors}

From the present research, the interviewed Saudi teachers, irrespective of their subject domain, depend on a limited number of ICT tools, very few of which can be found in the classroom. The technical availability of ICTs is the main primary hindrance to more widespread adoption. With a limited access of ICT tools the Saudi teachers are not able to test their appropriateness in teacher practices. Science teachers are given priority with regard to ICT access in a school setting. In comparison with them, the teachers of Arabic are constrained in their ICT usage because of the shortages of ICT in the classroom and insufficient technical support in schools. The technical service of the available ICTs is the main problem; the second problem is the insufficient availability of ICT tools in the classroom. Saudi teachers of mathematics value ICT for the possibility of representing geometric shapes that they used to draw by hand. These teachers solve technical issues by looking for the information on the Internet. The mathematics teachers think that teachers should be adept at using ICT, which may be achieved via training and refresher courses.

\section{Political implementation factors}

The Saudi teachers claim that it is the responsibility of the Ministry of Education to supervise mandatory uses of ICT in schools. They strongly believe that the Ministry of Education has no clear vision about how to supervise the ongoing ICT-related reform at the national level. The presence of ICTs leaves the Saudi teachers by themselves in selecting tools, preparing lessons, and deciding on the appropriateness of the available tools. Although they are mandatory ICT adopters, nobody supports and motivates them in their readiness for using ICT. Thus, the mandatory context fails to meet expectations with regard to a well-planned process of ICT integration. The formal mandate splits the difference between early, pre-reform ICT adopters, and late, mandatory adopters. It uniforms all the Saudi teachers, reducing the individual initiative of early adopters who lack administrative support and appraisal. The call for transformative change is not radical because the Saudi teachers are limited in their resources and training skills.

\section{Cultural implementation factors}

From the present findings, there is no ICT-related culture of ICT integration in Saudi secondary schools that will guarantee a continuity of the transition from ICT adoption across ICT implementation to ICT integration. The Saudi teachers are satisfied with their teacher practices independent of their ICT uses, which they consider to be complementary to the traditional methods of teaching.

The Saudi teachers who claim that there is no drastic change in the educational environment with the mandatory use of ICT, think that an ICT-competent, trained teacher is ideally situated for the future. Enthusiastic teachers are neither praised nor rewarded, and only some administrators support them. There is no culture of supervising ICT implementation by the Ministry of Education. From their own experience, the Saudi teachers believe that ICT tools help them alter traditional methods of explanation and revising the material, enhance student attention, interaction, and involvement. Saudi students become motivated to participate in an environment that is modernized due to the presence of ICT tools. Teacher performance gradually increases due to training courses and a better understanding of ICT as an effective tool for saving time and effort. The Saudi teachers claim that ICT uses need to be adapted to conventional methods. On 
International Journal on Integrating Technology in Education (IJITE) Vol.8, No.2, June 2019

the whole, the Saudi teachers think that their subject domains are not heavily dependent on ICT use.

A new culture of ICT integration in Saudi secondary schools can connect an ICT-competent teacher with his or her ability to use appropriate tools in order to improve teacher performance. Effective teachers are sensitive to personal growth which they link to ICT use in schools. They connect ICT usage with a changing classroom atmosphere that is characterized by fun, vitality, an improved ability to explain, and better student concentration. They know that the presence of ICT will change teaching methods that are based on modern tools. A strong belief in the presence of ICT in schools will direct teachers toward experimenting with new methods.

\section{The power of a mandate}

There are both benefits and faults to the mandatory presence of ICT tools in the Saudi secondary school context. The educational system benefits by maintaining the mandated presence of ICT in secondary schools. First, there is no segregation concerning the presence of ICT tools in secondary schools. There is no evidence that schools for boys are better equipped than schools for girls. There is no evidence that male teachers are better trained and competent in ICT usage than female teachers. Second, ICT adoption in Saudi secondary schools is universal. Third, all teachers have to meet a requirement for using ICT tools in their practice. Fourth, teachers have to attend training courses so they are not hindered by their inexperience using ICT.

However, it is more problematic for more experienced teachers to move from ICT adoption to higher stages of concern and levels of use. Novices gain from universal ICT adoption but the experienced teachers have to reconsider their ICT-related efforts in the context of less access to limited ICT tools since it is mandatory for all teaching staff to use ICT tools from time to time. Saudi schools are not properly funded to satisfy teachers' needs for ICT tools. The collected data have indicated that mandatory uses of ICT impede further development toward widespread ICT integration because both administrators and teachers rely on further instructions and fail to implement collectively developed initiatives in each school setting.

\section{CONCLUSION}

Saudi secondary school teachers of mathematics, science, and Arabic are ICT adopters due to a mandate within the ongoing secondary school reform. This fact has blurred the difference between early adopters and late adopters of ICT tools in the Saudi context. The mandate is the main driver behind ICT integration in secondary schools but it is not enough to trigger the ICTrelated educational reform by the mandate. Technically, politically, and culturally Saudi schools are poorly prepared for a change paradigm. There is a strong need for developing Saudi integration pedagogy that is grounded in Islamic values and traditions and makes plans for the phased integration of ICT in a strategic manner with a long-term perspective. Integration pedagogy will be developed by teachers who are ICT implementers within the context of the excellent availability of ICT tools, the effective training of ICT implementers, and the administrative support of all initiatives and the development of teachers as ICT implementers. Saudi Arabia has Islamic pillars of high quality, excellence, spirituality, and holism that will contribute to ICT integration in the country. Such integration is consistent with the harmony with our traditions and wiliness to achieve perfection without losing our national identity. In comparison with many other countries, Saudi Arabia has had relatively little experience teaching with technology. Its short-term goal is to create an infrastructure that can be beneficial for enacting change in teacher practices and continual teacher development directed toward ICT implementation in the classroom. 
International Journal on Integrating Technology in Education (IJITE) Vol.8, No.2, June 2019

ICT adoption and further adaptation within the overall process of ICT integration need to be grounded in Islamic values and traditions that are transformed towards more openness to the outside influences due to the presence of technology in Saudi secondary schools. The transition from ICT adoption means transformative change in the direction of integrating Saudi schools into current, globally recognized ICT-related strategies by giving more freedom to Saudi teachers to become effective. The Saudi collective identity can be used as a pillar of new ICT-related culture in the system of education, so that teachers can collegially discuss culturally appropriate ICT tools without authoritative recommendations from the Ministry of Education. Transformative change is grounded in the initiative of teachers who join their efforts with a view to changing an educational environment in Saudi Arabia.

\section{RECOMMENDATIONS}

Integration of ICT in the Saudi context should be based on such integration strategies: 1) a continuity of phased ICT integration with an emphasis on overcoming mechanical levels of use that is a feature of ICT implementation in the Saudi schools studied in this research; 2) regular monitoring and evaluation of implementation effectiveness with regard to appropriate uses of ICT to encourage both early and late adopters of ICT tools to drive from one phase to another, so that ICT integration would involve the overall education system; 3) there is a need for a change paradigm at both national and school levels whose standardized ICT uses in given subject domains will be integrated into ICT-related innovative teacher practices; teachers should be awarded for their creative and appropriate ICT uses and their experience should be discussed among their colleagues that teach the same subject domains; 4) Saudi schools should become integrated schools with pedagogical content knowledge that favors ICT integration due to systemic uses of ICT tools, availability of ICT tools in classroom settings, excellent training opportunities, and strategic planning of ICT integration that is reflected in the school curriculum.

\section{REFERENCES}

[1] Al-Kinani, M. (July 18, 2014). SR9 billion Tatweer project set to transform education [WWW document] URL

http://www.saudigazette.com/sa/index.cfm?method=home.gcon\&contemtID=2008081814710.

[2] Alshumaim, Y. \& Alhassan, R. (2010). Current Availability and Use of ICT among Secondary EFL Teachers in Saudi Arabia: Possibilities and Reality. In Z. Abas et al. (eds.), Proceedings of Global Learning Asia Pacific 2010 (pp. 523-532). Chesapeake, VA: AACE.

[3] Alwani, A.E.S. \& Soomro, S. (2010). Barriers to effective use of information technology in science education at Yanbu Kingdom of Saudi Arabia. E-Learning Experiences and Future. [WWW document] URL http://www.intechopen.com/articles/show/title/barriers-to-effective-use-ofinformation-technology-in-science-education-at-yanbu-kingdom-of-saudi-a

[4] Garcia-Valcarcel, A., Basilotta, V., \& Salamanca, C.L. (2014).ICT in collaborative learning in the classrooms of primary and secondary education. Communicar, 42 (XXI), Media Education Research Journal, ISSN: 1134-3478, 65-74.

[5] Hall, G.E. (2010). Technology's Achilles heel: Achieving high-quality implementation. JRTE, 42 (3), 231-253.

[6] Jones, N. \& O'Shea, J. (2004). Challenging hierarchies: The impact of e-learning. Higher Education, 48 (3), 379-395.

[7] Klein, K.J. \& Knight, A.P. (2005). Innovation implementation: Overcoming the challenge. Current Directions in Psychological Science, 14 (5), 243-246. 
International Journal on Integrating Technology in Education (IJITE) Vol.8, No.2, June 2019

[8] McGrory, R.W. (2004). A framework for understanding teaching with the Internet. American Educational Research Journal, 41 (2), 447-488.

[9] Merriam, S.B. (2009). Qualitative research: A guide to Design and Implementation. San Francisco, CA: John Wiley \& Sons.

[10] Oyaid, A.A. (2009). Education Policy in Saudi Arabia and its Relation to Secondary School Teachers' ICT Use, Perceptions, and Views of the Future of ICT in Education. PhD, University of Exeter.

[11] Passey, D. (2006). Technology enhancing learning: analyzing uses of information and communication technologies by primary and secondary school pupils with learning frameworks. The Curriculum Journal, 17 (2), 139-166.

[12] Passey, D. (2010). Mobile learning in school contexts: Can teachers alone make it happen? IEEE Transactions on Learning Technologies, 3 (1), 68-91.

[13] Richardson, J.W. (2011). Challenges of adopting the use of technology in less developed countries: the case of Cambodia. Comparative Education Review, 55 (1), 008-029.

[14] Rogers, M.E. (2003). Diffusion of innovations (5th ed). New York: The Free Press.

[15] Smart, J.C. (ed.) (2010). Higher Education: Handbook of Theory and Research. Vol. 25. Heidelberg, L., \& N.Y.: Springer.

[16] Wiggins, G. \& McTighe, J. (2007). Schooling by Design: Mission, Action, and Achievement. Alexandria, VA: Association for Supervision and Curriculum Development.

[17] Yamagata-Lynch, L.C. (2010). Activity systems analysis methods: Understanding complex learning environments. New York, Dordrecht, Heidelberg, \& London: Springer.

\section{AUTHORS}

Abdullah Alenezi, Dr. of Education, is Assistant Professor in the Educational Technology Department, Faculty of Education, Northern Borders University, Saudi Arabia (email: abdullah.a.alenezi@nbu.edu.sa). His major areas of interest and expertise are: organizational change, teaching and learning ou tcomes arising from uses of leadingedge technologies, implementation and management of leading-edge technologies at the local authority and individual institution levels, uses and impacts of technologies and technology-based resources in formal educational environments, distance learning and training, and technology integration in the Saudi context. 